\title{
Antagonistic regulation of the meristemoid-to-guard mother-cell-transition
}

\author{
Laura Serna* \\ Facultad de Ciencias del Medio Ambiente y Bioquímica, Universidad de Castilla-La Mancha, Toledo, Spain \\ *Correspondence: laura.serna@uclm.es \\ Edited by: \\ John Schiefelbein, University of Michigan, USA
}

Keywords: SPCH, MUTE, meristemoid self-renewal, guard mother cell fate, MAPK

The building of a multicellular organism from a single cell is the result of coordinated acquisition of different cell identities in an ordered spatial arrangement. But, how do cells learn about their identity? Stomatal development in Arabidopsis provides perhaps one of the most tractable contexts in which to examine concepts of cell fate determination, as a variety of lineage tracing techniques, including long-term confocal time lapse imaging (Peterson and Torii, 2012), can be deployed in different genetic contexts and environmental conditions to trace the history of only a few cell types. In this essay, I focus on the choice between meristemoid cell self-renewal, in which one of daughters of a dividing meristemoid retains the properties of the parent cell, and its transition through guard mother cell (GMC) fate to produce stomata.

In Arabidopsis, stomatal development, which starts at the tip of the leaf and proceeds basipetally, takes place through a series of stereotyped yet flexible cell division pattern (Lau and Bergmann, 2012; Pillitteri and Torii, 2012). The first sign of stomatal development is an unequal cell division from a protodermal cell called the meristemoid mother cell (MMC). This cell division produces a small triangular meristemoid and a larger neighboring cell. Meristemoids are self-renewing cells that divide (amplifying divisions) in an inward spiral and always yield a larger cell and a smaller meristemoid that maintains its self-renewal activity. The meristemoid eventually loses its self-renewal character and adopts a rounded shape giving rise to the GMC. The GMC undergoes an equal and symmetric cell division that generates the paired guard cells. Some of the larger cells that result from the unequal divisions of MMCs or meristemoids and that come into contact with the stoma (or its precursor) can adopt MMC fate initiating the cell division pattern that culminates with stomatal formation. Others differentiate into pavement cells. This lineage is responsible for generating the majority of the epidermal cells in the leaves (Geisler et al., 2000).

All stomatal lineages originate by an unequal division, but the number of subsequent cell divisions is not fixed, and it varies from zero to three. For example, the study of cell divisions through time using serial imprints revealed that, in the leaves (abaxial side) of C24 ecotype, $44 \%$ of complexes develop their stomata prematurely, that is, after the second, or even the first, unequal cell division (Berger and Altmann, 2000). Similar studies in Columbia background (abaxial epidermis of leaves and cotyledons) showed that $66 \%$ of their stomata develop also after the first or second unequal cell division (Geisler et al., 2000). Clonal analysis in the leaves (adaxial side) of Landsberg erecta ecotype also showed some flexibility with at least $13 \%$ of the complexes developing stomata prematurely (Serna et al., 2002). The differences in the degree of flexibility of stomatal development among different studies could be due to the genetic background, the face analyzed, the growth conditions and/or the methodology used to trace stomatal lineages. Anyway, what is certain is that, a greater or lesser extent, the number of amplifying divisions that take place before GMC formation is flexible. More recently, long-term confocal time lapse imaging in Arabidopsis leaves underlined also this variability in the number of amplifying divisions (Robinson et al., 2011). But, what are the molecular bases of this plasticity?
Time-lapse confocal imaging in live leaves showed that the basic helixloop-helix (bHLH) factor SPEECHLESS $(\mathrm{SPCH})$ locates in MMCs and meristemoids, and disappears in GMCs. This finding strongly suggests a role for $\mathrm{SPCH}$, which drives the cell division that initiates the stomatal-cell lineage (MacAlister et al., 2007; Pillitteri et al., 2007), in the maintenance of meristemoid self-renewal activity in the leaves (Robinson et al., 2011). Agree with this interpretation, and suggesting that the proposed role of $S P C H$ in leaves extends to other plant organs, meristemoids of the pedicel epidermis of the weak spch-2 mutant undergo significantly fewer amplifying divisions compared with wild type plants (MacAlister et al., 2007). In addition to SPCH, MAPKs also provide flexibility to stomatal development through repression of the meristemoidguard mother cell switch (Lampard et al., 2009): constitutive activation, beginning in meristemoids, of either the mitogenactivated protein kinases (MAPK) kinase kinase YODA (YDA) or the MAPK kinases MKK4, MKK5, MKK7 or MKK9 prevents stomatal formation giving rise to an epidermis consisting of pavement cells and arrested meristemoids. Because both MKK4 and MKK5 function upstream of the MAP kinases MPK3 and MPK6 during stomatal development (Wang et al., 2007), it is expected that constitutive activation, beginning in meristemoids, of MPK3 or MPK6 also blocks GMC formation. If this is true, and given that MPK3 and MPK6 phosphorylate SPCH protein in vitro (Lampard et al., 2008), these phosphorylation events may activate $\mathrm{SPCH}$ function in meristemoids, promoting their selfrenewal behavior and so repressing their transition to guard-mother cell (Figure 1). This scenario contrasts with that in which 


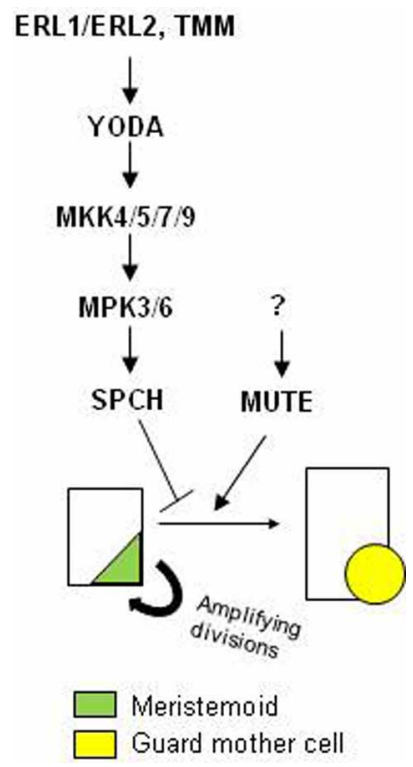

FIGURE 1 | Model for the regulation of the self-renewal behavior of the meristemoids and their transition to guard mother cell (GMC) fate. Predominance of $\mathrm{SPCH}$, which is activated by YDA MAPK module, inhibits the meristemoid-to-GMC transition by promoting the self-renewal behavior of the meristemoids. In contrast, predominance of MUTE represses the amplifying divisions of the meristemoids and enhances their transition through the GMC fate. GMC symmetrically divides to produce paired-guard cells (not shown). The components upstream of MUTE remain unknown. SCRM1 and SCRM2 function in this transition through direct interaction with SPCH and MUTE (not shown).

SPCH hyper-phosphorylation by both MPK3 and MPK5 suppresses its activity preventing the first unequal cell division of stomatal development (Lampard et al., 2008).

The ERECTA-family leucine-rich repeat receptor-like kinases members ERECTA-LIKE1 (ERL1) and ERECTALIKE2 (ERL2) maintain the division activity of the meristemoids and prevent them from differentiating into GMCs (Shpak et al., 2005): erll, erl2 and erl1 erl2 mutants show a reduction in the number of larger cells that surround the stoma (or its precursor), which arise from amplifying divisions. Like ERL1 and $E R L 2$, both the subtilisin-related extracellular protease STOMATAL DENSITY AND DISTRIBUTION1 (SDD1) and the plasma membrane-anchored leucinerich repeat receptor-like protein $T O O$
MANY MOUTHS (TMM) have been also involved in the maintaining of the self-renewal activity of the meristemoids, with sdd1-1 and tmm mutants undergoing also less amplifying divisions than wild-type plants (Berger and Altmann, 2000; Geisler et al., 2000; Bhave et al., 2009). Because TMM associates with ERL1 in vivo (Lee et al., 2012), the formation of heterodimeric complexes between TMM and ER1, and most probably between TMM and ERL2, might be required for the initiation of this signaling cascade. Moreover, the fact that constitutive activation of YDA suppresses the defects of tmm places this extracellular signaling upstream of YDA (Bergmann et al., 2004). It is known that these receptors interact and are activated by peptide ligands of the EPIDERMAL PATTERNING FACTOR (EPF)/EPIDERMAL PATTERNING FACTOR-LIKE (EPFL)-family (Torii, 2012). However, at the moment, no peptide ligand has been directly involved in the self-renewal activity of the meristemoids.

MUTE also encodes a bHLH protein, which, in addition, exhibits high homology with SPCH (Pillitteri et al., 2007). The loss-of-function mute mutant lacks stomata but develops meristemoids that arrest after excessive amplifying cell divisions that take place in an inward-spiral pattern (MacAlister et al., 2007; Pillitteri et al., 2007). This suggests that MUTE represses self-renewal activity of the meristemoids and induces GMC formation. Both MUTE promoter activity and the MUTE protein localization are restricted to a subset of meristemoids (MacAlister et al., 2007; Pillitteri et al., 2007), which presumably will undergo GMC transition. Interestingly, MUTE does not seem to be a substrate of either MPK3 or MPK6 (Lampard et al., 2008). Even more, MUTE is phosphorylated in vitro by the MAP kinase MPK4. However, both lossof-function and gain-of-function of the MAPK kinase kinase MEKK1, which acts upstream of MPK4 (Asai et al., 2002), do not induce any effect on stomatal development (Wang et al., 2007). In addition, the expression, beginning in meristemoids (or MMCs), of constitutively activate MAPK kinase kinase MKK1 or MKK2, which phosphorylate MPK4 (Popescu et al., 2009), also confers no apparent effect on the control of stomatal development, including meristemoid self-renewal activity (Lampard et al., 2009). Then, if MPK4 phosphorylates MUTE in meristemoids, this phosphorylation event should not be correlated with the MUTE function in the control of the meristemoid-toguard mother-cell-transition. If this is true, both loss- and gain-of-function of MPK4 plants should exhibit no effect on stomatal development.

Together, these finding suggest that at least two parallel pathways control the switch from meristemoid to GMC (Figure 1):(1) a pathway that controls SPCH function, and (2) an unknown pathway that regulates the activity of MUTE. Predominance of MUTE pathway may repress meristemoid self-renewal behavior, accelerating stomata formation. In contrast, predominance of SPCH pathway may induce the opposite effect, promoting self-renewal behavior of the meristemoids, and delaying GMC formation. In addition, RT-PCR analysis showed that SPCH promotes its own transcription and the transcription of MUTE (MacAlister et al., 2007; Pillitteri et al., 2007). Genetic and biochemical data also suggest that both SCRM1 and SCRM2 function in this transition through direct interaction with SPCH and MUTE (Kanaoka et al., 2008).

Stomatal number, and so gas exchange with the atmosphere, depends on the number of MMCs formed and on how long it takes for GMCs to divide. Since stomata premature formation reduces the distance among neighboring stomata, and vice versa, a coordinated control of selfrenewal of meristemoids and their transition to GMC fate is fundamental to avoid maladaptive responses. Meristemoids may perceive signals, adjusting the levels of SPCH vs. MUTE activity, in order to mount physiologically appropriate developmental responses. But, how could these signals trigger the regulation of $\mathrm{SPCH}$ and/or MUTE activity? Agree with the general view that MAPK modules are integrating point of multiple signals, several studies have highlighted that YDAMAPK module is a point of integration for communicating brassinosteroids and light signaling to stomatal development (Kang et al., 2009; Kim et al., 2012; Khan et al., 2013). Brassinosteroids, through 
the glycogen synthase kinase 3-like kinase BRASSINOSTEROID INSENSITIVE 2, can also regulate $\mathrm{SPCH}$ activity directly (Gudesblat et al., 2012), which, most probably, takes place in situations that trigger a reduction of YDA-MAPK levels (Serna, 2013). ABA also controls stomatal development (Tanaka et al., 2013), and YDA-MAPK module may also serve as a transmitter of the ABA-dependent cascade. Certainly, MPK6 is a target of ABSCISIC ACID-INSENSITIVE 1 (Leung et al., 2006), which represses stomatal formation (Tanaka et al., 2013). Considering that YDA-MAPK module controls the meristemoid to GMC transition, it is likely that these factors also regulate this switch. MUTE may also perceive, directly or indirectly through their yet unknown upstream regulators, systemic signals to optimize the ratio of stomata vs. pavement cells to the state of the plant and the environment.

Interestingly, analysis of static pictures showed that the number of meristemoids and GMCs is not constant throughout development (Geisler and Sack, 2002). Instead, there are periods when, for example, both meristemoids and GMCs increase and decrease, respectively (Geisler and Sack, 2002). This suggests that, in this particular period, meristemoids receive signals that accentuate the predominance of SPCH pathway, thus prolonging their self-renewal capacity. There are also periods when meristemoids drop, while GMCs increase (Geisler and Sack, 2002), suggesting, in this period, a predominance of MUTE pathway in these meristemoids, even though they had divided a variable number of times. Agree with this interpretation, data from serial imprints showed that in some temporal windows the majority of meristemoids become mature stomata, even though they do it prematurely (Geisler and Sack, 2002). Meristemoids also pause divisions when subject to mild osmotic stress, and quickly recover them once this stress is alleviated (Skirycz et al., 2011). Mild osmotic stress may block MUTE activity, which in absence, or under low levels, of SPCH activity, would pause meristemoid progression. Selective activation of either SPCH or MUTE may resume meristemoid self-renewal capacity or its transition to GMC fate, respectively. Supporting this interpretation, arrested meristemoids of 13 days-old iMUTEmute plants transit to GMC fate upon late (13 days post-germination) induction of $\beta$-estradiol-dependent MUTE expression (Triviño et al., 2013).

The story gets more complicated when we consider stomatal development in the context of the entire developing leaf, instead of considering individual lineages. For example, if two meristemoids from two separate lineages arise adjacent to each other, they do not progress to become stomata, but instead one of them undergoes an additional cell division to prevent the physical contact with its neighbor, or even undergoes a transdifferentiation process (Geisler et al., 2000). This example highlights that cell-to-cell signaling guides meristemoid fate, most probably, by imposing to that dictated by environmental factors or phytohormones.

Detailed knowledge about the process that regulates self-renewal of meristemoids and their transit to GMC fate is crucial to enable better adapted and more productive plants to local site conditions. To deep into the understanding of the control of this step is necessary to identify the components acting upstream of MUTE. Challenges for the future also include verifying that MPK3 and MPK6 are downstream components of the four MAPK kinases, MKK4, MKK5, MKK7, and MKK9, in the meristemoid to GMC transition, and that MPK3 and MPK6 trigger SPCH regulation in this switch. Identifying the components upstream of TMM-ERL1/2 is also needed.

\section{REFERENCES}

Asai, T., Tena, G., Plotnikova, J., Willmann, M. R., Chiu, W. L., Gomez-Gomez, L., et al. (2002). MAP kinase signalling cascade in Arabidopsis innate immunity. Nature 415, 977-983. doi: 10.1038/415977a

Berger, D., and Altmann, T. (2000). A subtilisinlike serine protease involved in the regulation of stomatal density and distribution in Arabidopsis thaliana. Genes Dev. 14, 1119-1131. doi: 10.1101/gad.14.9.1119

Bergmann, D. C., Lukowitz, W., and Somerville, C. R. (2004). Stomatal development and pattern controlled by a MAPKK kinase. Science 304, 1494-1497. doi: 10.1126/science.1096014

Bhave, N. S., Veley, K. M., Nadeau, J. A., Lucas, J. R., Bhave, S. L., and Sack, F. D. (2009). TOO MANY MOUTHS promotes cell fate progression in stomatal development of Arabidopsis stems. Planta 229, 357-367. doi: 10.1007/s00425-008-0835-9

Geisler, M., Nadeau, J., and Sack, F. D. (2000). Oriented asymmetric divisions that generate the stomatal spacing pattern in Arabidopsis are disrupted by the too many mouths mutation. Plant Cell 12, 2075-2086. doi: 10.1105/tpc.12.11.2075

Geisler, M. J., and Sack, F. D. (2002). Variable timing of developmental progression in the stomatal pathway in Arabidopsis cotyledons. New Phytol. 153, 469-476. doi: 10.1046/j.0028-646X.2001.00332.x

Gudesblat, G. E., Schneider-Pizon, J., Betti, C., Mayerhofer, J., Vanhoutte, I., van Dongen, W., et al. (2012). SPEECHLESS integrates brassinosteroid and stomata signalling pathways. Nat. Cell Biol. 14, 548-554. doi: 10.1038/ncb2471

Kanaoka, M. M., Pillitteri, L. J., Fujii, H., Yoshida, Y., Bogenschutz, N. L., Takabayashi, J., et al. (2008). SCREAM/ICE1 and SCREAM2 specify three cellstate transitional steps leading to arabidopsis stomatal differentiation. Plant Cell 20, 1775-1185. doi: 10.1105/tpc.108.060848

Kang, C. Y., Lian, H. L., Wang, F. F., Huang, J. R., and Yang, H. Q. (2009). Cryptochromes, phytochromes, and COP1 regulate light-controlled stomatal development in Arabidopsis. Plant Cell 21, 2624-2641. doi: 10.1105/tpc.109.069765

Khan, M., Rozhon, W., Bigeard, J., Pflieger, D., Husar, S., Pitzschke, A., et al. (2013). Brassinosteroidregulated GSK3/shaggy-like kinases phosphorylate mitogen-activated protein (MAP) kinase kinases, which control stomata development in Arabidopsis thaliana. J. Biol. Chem. 288, 7519-7527. doi: 10.1074/jbc.M112.384453

Kim, T.-W., Michniewicz, M., Bergmann, D. C., and Wang, Z.-Y. (2012). Brassinosteroid regulates stomatal development by GSK3-mediated inhibition of a MAPK pathway. Nature 482, 419-422. doi: $10.1038 /$ nature 10794

Lampard, G. R., Lukowitz, W., Ellis, B. E., and Bergmann, D. C. (2009). Novel and expanded roles for MAPK signaling in Arabidopsis stomatal cell fate revealed by cell type-specific manipulations. Plant Cell 21, 3506-3517. doi: 10.1105/tpc.109.070110

Lampard, G. R., MacAlister, C. A., and Bergmann, D. C. (2008). Arabidopsis stomatal initiation is controlled by MAPK-mediated regulation of the bHLH SPEECHLESS. Science 322, 1113-1116. doi: 10.1126/science. 1162263

Lau, O. S., and Bergmann, D. C. (2012). Stomatal development: a plant's perspective on cell polarity, cell fate transitions and intercellular communication. Development 139, 3683-3692. doi: 10.1242/dev.080523

Lee, J. S., Kuroha, T., Hnilova, M., Khatayevich, D., Kanaoka, M. M., McAbee, J. M., et al. (2012) Direct interaction of ligand-receptor pairs specifying stomatal patterning. Genes Dev. 26, 126-136. doi: 10.1101/gad.179895.111

Leung, J., Orfanidi, S., Chefdor, F., Mészaros, T., Bolte, S., Mizoguchi, T., et al. (2006). Antagonistic interaction between MAP kinase and protein phosphatase 2C in stress recovery. Plant Sci. 171, 596-606. doi: 10.1016/j.plantsci.2006.06.009

MacAlister, C. A., Ohashi-Ito, K., and Bergmann, D. C. (2007). Transcription factor control of asymmetric cell divisions that establish the stomatal lineage. Nature 445, 537-540. doi: 10.1038 /nature05491

Peterson, K. M., and Torii, K. U. (2012). Long-term, high-resolution confocal time lapse imaging of Arabidopsis cotyledon epidermis during germination. J. Vis. Exp. 70:e4426. doi: 10.3791/4426 
Pillitteri, L. J., Sloan, D. B., Bogenschutz, N. L., and Torii, K. U. (2007). Termination of asymmetric cell division and differentiation of stomata. Nature 445, 501-505. doi: 10.1038/nature05467

Pillitteri, L. J., and Torii, K. U. (2012). Mechanisms of stomatal development. Annu. Rev. Plant Biol. 63, 591-614. doi: 10.1146/annurev-arplant-042811105451

Popescu, S. C., Popescu, G. V., Bachan, S., Zhang, Z., Gerstein, M., Snyder, M., et al. (2009). MAPK target networks in Arabidopsis thaliana revealed using functional protein microarrays. Genes Dev. 23, 80-92. doi: 10.1101/gad. 1740009

Robinson, S., Barbier de Reuille, P., Chan, J., Bergmann, D., Prusinkiewicz, P., and Coen, E. (2011). Generation of spatial patterns through cell polarity switching. Science 333, 1436-1440. doi: 10.1126/science. 1202185

Serna, L. (2013). What causes opposing actions of brassinosteroids on stomatal development? Plant Physiol. 162, 3-8. doi: 10.1104/pp.112.213058

Serna, L., Torres-Contreras, J., and Fenoll, C. (2002). Clonal analysis of stomatal development and patterning in Arabidopsis leaves. Dev. Biol. 241, 24-33. doi: 10.1006/dbio.2001.0506
Shpak, E. D., McAbee, J. M., Pillitteri, L. J., and Torii, K. U. (2005). Stomatal patterning and differentiation by synergistic interactions of receptor kinases. Science 309, 290-293. doi: 10.1126/science. 1109710

Skirycz, A., Claeys, H., De Bodt, S., Oikawa, A., Shinoda, S., Andriankaja, M., et al. (2011). Pause-and-stop: the effects of osmotic stress on cell proliferation during early leaf development in Arabidopsis and a role for ethylene signaling in cell cycle arrest. Plant Cell 23, 1876-1888. doi: 10.1105/tpc.111. 084160

Tanaka, Y., Sugano, S. S., Shimada, T., and HaraNishimura, I. (2013). Enhancement of leaf photosynthetic capacity through increased stomatal density in Arabidopsis. New Phytol. 198, 757-764. doi: 10.1111/nph.12186

Torii, K. U. (2012). Mix-and-match: ligandreceptor pairs in stomatal development and beyond. Trends Plant Sci. 17, 711-719. doi: 10.1016/j.tplants.2012.06.013

Triviño, M., Martín-Trillo, M., Ballesteros, I., Delgado, D., de Marcos, A., Desvoyes, B., et al. (2013). Timely expression of the Arabidopsis stomafate master regulator MUTE is required for specification of other epidermal cell types. Plant J. 75, 808-822. doi: 10.1111/tpj.12244

Wang, H., Ngwenyama, N., Liu, Y., Walker, J. C., and Zhang, S. (2007). Stomatal development and patterning are regulated by environmentally responsive mitogen-activated protein kinases in Arabidopsis. Plant Cell 19, 63-73. doi: 10.1105/tpc.106.048298

Received: 29 August 2013; accepted: 20 September 2013; published online: 11 October 2013.

Citation: Serna L (2013) Antagonistic regulation of the meristemoid-to-guard mother-cell-transition. Front. Plant Sci. 4:401. doi: 10.3389/fpls.2013.00401

This article was submitted to Plant Cell Biology, a section of the journal Frontiers in Plant Science.

Copyright (C) 2013 Serna. This is an open-access article distributed under the terms of the Creative Commons Attribution License (CC BY). The use, distribution or reproduction in other forums is permitted, provided the original author(s) or licensor are credited and that the original publication in this journal is cited, in accordance with accepted academic practice. No use, distribution or reproduction is permitted which does not comply with these terms. 